\title{
LA PROPUESTA DE UNA ESCRITURA \\ (En homenaje a Rodolfo Walsh) ${ }^{1}$
}

\author{
POR \\ ANA MARIA AMAR SANCHEZ
}

La aparición en los últimos años de un número considerable de textos en lengua castellana, como algunas novelas de Jorge Semprún, El desvanecimiento o Autobiografía de Federico Sánchez; Los periodistas, de Vicente Leñero, y recientemente Recuerdo de la muerte, de Miguel Bonasso, se vincula a las propuestas de la denominada "Novela de no fícción» o «Novela periodística». Suele pensarse en los narradores norteamericanos, en especial Capote y Mailer, como los iniciadores de este género, surgido en los años sesenta (aunque haya antecedentes dispersos que no conforman un corpus importante); sin embargo, nueve años antes que Capote escribiera $A$ sangre fría (1965), Rodolfo Walsh había publicado en Buenos Aires Operación masacre (1956) y comenzado así la elaboración de una forma que iba a intentar romper, en el caso de él particularmente, con todas las fronteras que delimitan lo que es literatura y lo que son géneros «aceptables» y «menores».

Por otra parte, la producción de Rodolfo Walsh se inserta en un proyecto mucho más amplio que el estrictamente literario de construir una clase de novela como respuesta alternativa a un realismo ya desgastado; compromete planos tan abarcadores como es el de la función del intelectual en los países latinoamericanos, la relación que une la práctica literaria con la política, el compromiso a través de una producción específica que no quede reducida a un ejercicio brillante de la inteligencia ni a un panfleto político. Sin duda, no es ajena a esto la diversidad de repercusión lograda (por supuesto, en un contexto histórico y social muy diferente) por autores como Capote o Mailer y Walsh, una de las víctimas más lúcidas de la tragedia argentina de los últimos años.

${ }^{1}$ El material de este artículo forma parte de un trabajo, en preparación, sobre la narrativa de Rodolfo Walsh. 
Este trabajo intenta esbozar una reflexión en torno a las cuestiones teóricas que plantean sus tres textos de no ficción ${ }^{2}$; aunque un estudio sobre su producción debe abarcar la totalidad de ella: Walsh utiliza similares mecanismos de escritura, fusiona materiales de diverso origen, desestima los encasillamientos; reducirlo implica dejar a un lado la coherencia y la unidad de una práctica que destroza los límites entre literatura y los otros discursos.

E1 objetivo de este trabajo no es el de encontrar un marco «ilustre» de referencia para estos textos (sobre cuya denominación, «relato de no ficción», pesa el implícito prejuicio de que todo relato «normal» debe ser de ficción); no se trata de clasificarlos dentro de alguna tradición literaria prestigiosa o de intentar construir una teoría descriptiva o normativa que defina sus propiedades, y que termine por establecerse basándose en sus semejanzas o diferencias con la narrativa de ficción. Se intenta aquí señalar el campo teórico y las propuestas que los textos abren a la discusión, en dos planos que se entrecruzan necesariamente: en primer lugar, considerándolos como un espacio constituido, al mismo tiempo, por la adopción y cuestionamiento de diversos géneros; por lo tanto, como el ámbito donde se establece un sistema de relaciones dialógicas, en el sentido bajtiniano; determinar con quién dialogan, es decir, a quién reconocen o con quién polemizan, permite la delimitación de un campo intertextual entendido no sólo como el lugar de entrecruzamiento de códigos, como el espacio en que temas y procedimientos de una multiplicidad de textos se encuentran, sino también como un ámbito en el que un proyecto y una concepción de la literatura, que lleva implícita la elección de una forma, pueden plantearse discutir o elegir sus precursores, proponiendo, simultáneamente, la confrontación ideológica con otros sistemas literarios ${ }^{3}$.

En segundo término, esta narrativa problematiza y permite el cuestionamiento y revisión de algunas nociones que hacen a la reflexión teórica de la literatura: tales como qué significa ficcionalizar, cómo se ficcionaliza, cuáles son las relaciones entre lo real y lo ficcional; cómo se resuelve la discusión en torno al concepto de forma y sus implicaciones ideológicas. Estas cuestiones remiten a la ya clásica polémica sobre el realismo y la «forma adecuada» entre Lukács y Brecht: se puede ver cómo ambos planos se correlacionan, porque el análisis de estas categorías literarias lleva, nuevamente, al ámbito intertextual que privilegian estos textos.

${ }^{2}$ Operación masacre (1956), Caso Satanowsky (1958), ¿Quién mató a Rosendo? (1968).

${ }^{3}$ «E1 texto poético se produce en el movimiento complejo de una afirmación y de una negación de otro texto», en J. Kristeva, «Poésie et negativité», Sémiotique. Recherches pour une sémanalyse (París: Ed. du Seuil, 1969). 


\section{El INTERTEXTO PRIVILEGIADO: DIÁLOGO CON LOS PRECURSORES}

Se sabe que ningún relato es solamente un relato: en los tres textos considerados, Walsh se plantea algo más que denunciar o informar acerca de algunos crímenes políticos. El ha publicado primero en periódicos sus investigaciones, pero ese material, cuando se edita en forma de libro, es objeto de un trabajo de transformación (agregados, supresiones, montaje); hay una voluntad constructiva, se lo «literaturiza» y deja de ser un informe periodístico; se propone así un modo nuevo de hacer literatura. Su elección formal determina, implícitamente, el contacto con algunas propuestas o concepciones literarias y lo enfrenta con otras.

Entre las primeras, una actúa como intertexto fundamental e induce al lector latinoamericano de fines del siglo $\mathrm{xx}$ a una relectura y un interés renovado por un período aparentemente alejado en el espacio y en el tiempo. Walsh reactualiza el proyecto de algunos autores alemanes, en especial Brecht, Benjamin y Eisler, que durante la década de los treinta, en los momentos previos al triunfo del nazismo y luego en el exilio, retoman las posiciones de la «nueva objetividad» y del grupo de escritores rusos, nucleados en torno a la revista $L E F$, de la Unión Soviética, a mediados de los años veinte. El grupo, al que pertenecían Arvatov, Tretiakov y Maiakovskij, entre otros, había impugnado los principios de la novela realista «para la que carece de importancia la verdad y se preocupa de mantener la verosimilitud $\gg{ }^{4}$, reclamando una literatura de hechos, de datos verdaderos; con la misma perspectiva, el cineasta Vertov proponía el cine-ojo, en el que el montaje permite organizar un material exclusivamente documental.

De este modo, los autores alemanes mencionados, a los que puede agregarse Ottwalt ${ }^{5}$, piensan que está naciendo una nueva literatura que debe tomar en cuenta las necesidades de un nuevo público; rechazan el argumento y el narrador ficticio para construir la obra a partir de elementos documentales, pero trascendiendo la mera reproducción de los hechos. Es decir, se impugna el carácter ficcional de los relatos y se propone una literatura en la que lo representado adquiere valor estético mediante su autenticidad y por el nuevo campo de relaciones que el material descubre al ser transformado por el montaje; al mismo tiempo, se le asigna una

${ }^{4}$ Cita de LEF, en H. Gallas, Teoría marxista de la literatura (Buenos Aires: Siglo XXI, 1973).

${ }^{5}$ Ernest Ottwalt (1901-desaparecido en 1953) colaboró con Brecht, emigró en 1933 a la Unión Soviética, autor de un relato documental, Porque ellos saben lo que hacen, una novela de la justicia alemana. 
nueva función a esta forma, que debe informar y activar la comprensión política del lector.

En este contexto es fundamental la polémica entre Lukács y Brecht, que alcanzó su punto más agudo durante el exilio de ambos, entre los años 37 a 39, y en la que participan también Eisler y Benjamin. Estas discusiones permiten situar a Walsh en una tradición que enfrenta la perspectiva lukacsiana a favor de la escuela realista y de la noción de reflejo como único camino posible para una literatura comprometida. Tanto Brecht ${ }^{6}$ como Benjamin ${ }^{7}$ rechazan la defensa que hace Lukács del método narrativo tradicional y sostienen la historicidad de las formas: los nuevos temas exigen formas nuevas que se valgan de la evolución de los medios técnicos. Esta acentuación de la importancia del cambio formal como capaz de modificar la función de la literatura se opone a una concepción centrada en lo temático exclusivamente; al rechazar a esta última por considerarla políticamente ineficaz y estéticamente improductiva, ambos sostienen que los temas revolucionarios son fácilmente asimilables y neutralizados por el sistema; se hace así necesario encontrar nuevos modos de asegurar el efecto sobre el público. Sorprende la coincidencia entre estas formulaciones y las de Walsh, expresadas en un reportaje realizado por Ricardo Piglia ${ }^{8}$ : es irrelevante preguntarse acerca de si ha habido o no una influencia directa; importa, en cambio, señalar que hay un espacio común desde donde se piensa la literatura. Los textos de Walsh se postulan, de este modo, dentro de una tradición que propone un arte vinculado con lo político, pero para ello privilegia la renovación formal como único medio de lograr la desautomatización del lector; participan de un proyecto acerca de cómo hacer literatura y con qué objeto, a partir del cuestionamiento de los códigos aceptados y proponiendo nuevas alternativas.

Optar por una escritura que prescinda de lo ficticio y trabaje con material de la realidad sin ser por ello «realista», poniendo el acento en el montaje y el modo de organización del material, implica un rechazo del

\footnotetext{
${ }^{6}$ B. Brecht, El compromiso en literatura y arte (Barcelona: Ed. Península, 1973).

${ }^{7} \mathrm{~W}$. Benjamin, «El autor como productor», en Brecht, ensayos y conversaciones (Montevideo: Arca, 1976).

$s$ «... es probable... que un nuevo tipo de sociedad y nuevas formas de producción exijan un nuevo tipo de arte más documental, ... la denuncia traducida al arte de la novela se vuelve inofensiva, no molesta para nada, es decir, se sacraliza como arte... En un futuro (es posible que) ... lo que realmente sea apreciado en cuanto a arte sea la elaboración del testimonio o el documento ... evidentemente en el montaje, en la compaginación, en la selección, en el trabajo de investigación se abren inmensas posibilidades artísticas.» Reportaje de Ricardo Piglia a Rodolfo Walsh, marzo de 1970, en Un oscuro día de justicia (Buenos Aires: Siglo XXI, Colección mínima, 1973).
} 
concepto de verosimilitud como ilusión referencial, lo que Barthes llama «efecto de realidad»: intento de hacer creer que el texto se conforma a lo real, no a las propias leyes del género, máscara con que disfrazar el código, aparentando ser un discurso transparente que refleja directamente la realidad, es decir, enmascarando la ideología que lo funda.

Los textos de Walsh se distancian de este verosímil, manifestándose como un espacio de lucha entre códigos, renuncian a parecer «realistas» al optar por los hechos verdaderos y no los posibles; en efecto, tanto Operación masacre como los restantes se plantean siempre como discursos, son relatos de investigaciones acerca de hechos que, aunque reales y quizá por eso, son percibidos casi como inverosímiles ${ }^{9}$ : el lector se ve obligado a confrontarlos constantemente con su experiencia histórica y literaria.

Del mismo modo que los autores alemanes mencionados, Walsh intenta informar sobre las verdaderas condiciones de los hechos narrados, recurriendo a diversos tipos de discursos y a las técnicas que le proporcionan los medios de comunicación como el periodismo; desecha, así, la novela tradicional, con la cual «el lector recibiría la historia como cualquier otra, a lo sumo quedaría indignado... pero subsistiría la dificultad para comprender las conexiones sociales de los hechos individuales» ${ }^{10}$.

\section{DIÁlOGO Y TOMA DE DISTANCIA CON LOS CONTEMPORÁNEOS}

Las propuestas de los autores rusos y alemanes interesan, en la década de los treinta, a algunos narradores de los Estados Unidos; uno de los primeros en sentir su influencia es Dos Passos, que introduce en sus novelas textos periodísticos, a modo de flash, y montajes. Sin embargo, recién a partir de la década del sesenta, se configura y toma fuerza la novela de no ficción con autores como Capote, Mailer y Wolfe.

Los especialistas estadounidenses coinciden en ver esta narrativa como un fenómeno que surge en un momento de crisis, cuando los acontecimientos exceden la capacidad de comprensión, y, por otra parte, como una respuesta al desgaste de las formas realistas tradicionales, expresado por Mailer con la frase «la realidad ya no es realista». Es decir, que se conjugan una época de grandes cambios, que se venían gestando desde el fin de la Segunda Guerra, con un período de intensa experimentación en la ficción. Un intento de resolver ambas crisis estaría representado por lo

${ }^{9}$ «Livraga me cuenta su historia increíble; la creo en el acto. Así nace aquella investigación, este libro.» Operación masacre (Buenos Aires: Ed. de la Flor, 1972), p. 11 .

${ }^{10}$ H. Gallas, ob. cit 
que algunos críticos llaman «formas híbridas» ${ }^{11}$. De este modo, la consideración del surgimiento del género, relacionado con períodos de conmoción y crisis, plantearía como hipótesis la existencia de una presión referencial de la que no podrían hacerse cargo, aparentemente, los textos de ficción.

Por otra parte, la creciente influencia de los medios de comunicación llevaría a incorporar las técnicas características del periodismo, como el reportaje, permitiendo así un nuevo modo de compromiso personal. Sin embargo, la propuesta se despoja, entre los narradores norteamericanos, de la intencionalidad y función revolucionarias que quisieron otorgarle autores como Brecht $\mathfrak{u}$ Ottwalt, presentes también en Walsh; se trata en Capote o Mailer de un intento de renovación o experimentación literaria, que permite una denuncia, casi siempre parcial (en Walsh los hechos involucran el funcionamiento de la totalidad del sistema, al que hay que desenmascarar), en tanto que la rebeldía se convierte en una mera posibilidad frustrada (un ejemplo significativo es Los ejércitos de la noche, de Mailer); no hay esperanzas, ni tampoco tn proyecto de respuesta desde la literatura contra el sistema.

El género queda reducido a una de las tantas alternativas formales que la narrativa de los últimos treinta años ofrece como salida frente a la novela realista, diluyéndose la capacidad revulsiva y de propuesta rescatada por Walsh. El trabajo sobre sus textos de no ficción permitiría determinar la distancia que su producción establece con esta narrativa y señalar no sólo la diversidad de relaciones contextuales, sino especialmente las diferencias existentes en la concepción de la función de la literatura y del intelectual.

Si los textos de Walsh proponen ciertas líneas narrativas como sus precursoras, establecen distancias y puntos de contacto con otros ámbitos intertextuales contemporáneos, es necesario tener en cuenta un contexto esencial, en relación al cual se definen también, polémicamente: el de la literatura argentina producida en el mismo período.

Angel Rama considera sus relatos como el resultado de «una conjugación de las líneas tendenciales que se suceden en las culturas en conflicto ${ }^{12}$; esto es porque Walsh utiliza nuevos procedimientos que le propone la época, recoge géneros semiliterarios (el periodismo, la novela policial), rescata material desvalorizado por la cultura oficial y al mismo tiempo asume el contexto cultural, proponiendo un nuevo espacio al intelectual,

${ }^{11}$ John Hollowell, Fact and fiction. The new journalism and the non fiction novel (The University of North Carolina Press, 1977).

${ }_{12}$ Angel Rama, «Rodolfo Walsh: la narrativa en el conflicto de las culturas», en Literatura y clase social (México: Ed. Folios, 1983). 
no sólo por su compromiso, que va, en lo personal, mucho más allá de la denuncia, sino haciéndose cargo, a pesar de provenir de la cultura dominante, de una cultura silenciada.

Pero al llevar al campo de la literatura materiales provenientes de expresiones culturales marginales (en lo que se manifiesta un heredero de Arlt y Borges, a la vez que un precursor de la revalorización que en los años sesenta se hará de géneros poco prestigiosos para la cultura oficial), postula una nueva forma que quiere destruir los límites entre los géneros; dentro de una generación que se caracteriza por el regreso de la mayoría a tipos de narrativa realista, los textos de Walsh entablan un diálogo diferente con el lector, insertándose en una tradición proveniente de la cultura popular como es el «drama policial», de larga trayectoria en Europa (puesto que está relacionado con el folletín y los relatos de bandoleros) y en la Argentina, desde la aparición de las novelas de Ricardo Gutiérrez; relatos todos cuyo punto de contacto principal es la visión del sistema judicial como desacreditado, siendo el delincuente o el investigador un representante de la verdadera justicia.

Walsh cuestiona algunos de los conceptos más arraigados acerca de lo que es literatura, aportando propuestas para una narrativa nueva; su producción cumple así con las premisas que Benjamin consideraba indispensables cuando sostenía que «un autor que no enseña nada a los escritores no le enseña nada a nadie» ${ }^{13}$, es decir, cuando planteaba la exigencia de reflexionar en torno a su capacidad de aportar algo para el cambio funcional de la literatura.

Este es, posiblemente, uno de los motivos de su vigencia, mayor que la de otros autores idel mismo período, que permite a sus textos establecer un diálogo con el lector del presente, no sólo por la posibilidad de una relectura que los cargue de nuevas significaciones a la luz de los acontecimientos vividos en los últimos años, sino porque propone un camino, una vía diferente a la novela actual ${ }^{14}$.

\section{EL DIÁLOGO ENTRE LOS GÉNEROS: CONFRONTACION Y LUCHA}

Con los textos de Walsh se actualiza la polémica, tan debatida en los últimos años, en torno a los límites que determinan la pertenencia de una

${ }^{13}$ W. Benjamin, ob. cit.

${ }^{14}$ No es casual que, en la literatura argentina de los últimos años, una de las mejores tentativas, dando cuenta de un referente silenciado y ocultado, se canalice en el relato Recuerdo de la muerte (1984), de Miguel Bonasso, continuador de las propuestas de la no ficción de Walsh. 
obra al ámbito de la literatura y de un género; la reconsideración de éstos se problematiza por el uso de formas marginales en la literatura culta. Esta vuelta sobre el tema de los géneros para considerarlos de muy distinto modo que como un sistema normativo, pone el acento en su condición esencialmente histórica y social. Toda definición acerca de qué es literatura o qué géneros pertenecen a ella depende de factores extraliterarios, no hay criterios de evaluación que no sean de orden ideológico; los cambios en el modo de leer los textos y el punto de vista desde el cual se los juzga están sujetos a las variaciones producidas en el ámbito social: no hay ninguna propiedad esencial que defina a la literatura, ella es «lo que en cierta instancia social e histórica se entiende por literatura» ${ }^{15}$. Se va a delimitar, entonces, de acuerdo con lo que una clase social o ciertas instituciones consideran como tal: los factores históricos e ideológicos definen la aceptación de los textos y los límites de lo literario.

Por otra parte, el contacto mutuo entre los géneros es muy activo en ciertos períodos; se producen así modificaciones sustanciales en las formas fijadas por la tradición. Según sostiene Bajtin ${ }^{16}$, la novela es una forma nueva, en contacto con lo contemporáneo, que desde sus comienzos se apoyó en géneros extraliterarios para irse afianzando como tal. De este modo, la presencia de formas periodísticas en una época de predominio de los medios de comunicación de masas no debería resultar sorprendente; la interacción de diversos elementos a causa de factores extraliterarios, como son las nuevas circunstancias culturales, provoca deslizamientos en las jerarquías, y géneros como el periodístico o el policial pueden alcanzar el valor de dominante en determinado período. Una tradicional concepción, que ve la forma y la función literarias como partícipes de una esencia que escapa a lo histórico, rechaza esto; sólo viendo en qué medida los textos de Walsh subvierten esa ideología inmovilizante de la literatura, se comprende la resistencia que ha provocado todo intento de considerarlos dentro de ella.

La nueva forma narrativa que intenta Walsh se constituye esencialmente a partir de dos géneros de segundo orden, casi marginales, que sufren modificaciones al entrar en contacto. Este acercamiento los transforma y enfrenta, permitiendo una toma de distancia entre ellos: los textos apelan a los códigos del policial y del periodístico, pero en el encuentro ambos se cuestionan y destruyen, ponen en evidencia el verosímil del otro.

${ }^{15}$ Noé Jitrik, «Acción textual/acción sobre los textos», en Revista Iberoamericana, núms. 114-115 (enero-junio 1981).

${ }_{16}$ M. Bajtin, «Epopeya y novela», en Revista Eco (1977). 
En primer término, es evidente la filiación policial de la mayor parte de su narrativa; se ha sostenido que toma las dos clases del género en diferentes momentos de su producción: sus primeras novelas y cuentos. son ejemplos paradigmáticos del relato de enigma, en los que es nítida la huella borgiana, en tanto que los textos de no ficción estarían dentro de la llamada novela dura o negra. Sin embargo, los procedimientos de construcción se entrecruzan y perduran, transformados, en ambas líneas.

Por otra parte, la totalidad de su obra, incluyendo los relatos de ficción no policiales, comparte muchos mecanismos narrativos, constituyendo su producción un corpus por el que circulan elementos de diverso origen, cuyo análisis permitiría demostrar la unidad interna existente en su escritura y rechazar las clasificaciones en que normalmente se dividen sus textos. Un ejemplo de estos mecanismos es el tratamiento de lo que podría llamarse «lo omitido», que en el caso de sus primeros relatos policiales de enigma se manifiesta como rasgo del género, a través del escamoteo de información al lector, en la categoría narrador: éste, aunque parece darle todos los datos para el descubrimiento del culpable, siempre retacea pruebas y evita develar identidades. Esto se corresponde, en los relatos de no ficción, con la omisión de parte del proceso de investigación: «... no sé qué le decimos a través de la mirilla, qué promesa de silencio, qué clave oculta...» «¿Cómo hizo? Ya no recuerdo cómo hice» ${ }^{17}$. El narrador elude explicitar los medios por los que logró avanzar en ella, ya no para despistar al lector y mantener el suspense, sino para proteger al informante; pero el mecanismo constructivo es el mismo: él sabe más y lo disimula. El trabajo sobre «la omisión» se reitera, adquiriendo diversas características, en la totalidad de su obra, donde incluso hay casos en que determina el modo de construcción narrativo ${ }^{18}$.

No obstante, en este entretejido de rasgos con distinta procedencia prevalecen las inflexiones del relato «duro» norteamericano: más allá de compartir el modo de organizar o encauzar la investigación en torno a la cual se constituye el relato (aunque la ausencia casi de enigma, en la medida en que los lectores conocen los hechos y a los culpables, no impide mantener un suspenso, cuya elaborada construcción habla de la importancia de lo formal en estos textos y de su «literaturidad»), hay un común campo ideológico que liga los relatos de un Chandler o un Hammett con

${ }^{17}$ Operación masacre, ed. cit., pp. 13 y 15.

${ }_{18}$ Un ejemplo interesante es el cuento «Nota al pie» de Un kilo de oro (1967), en el que la organización gráfica determina un espacio en blanco entre los dos fragmentos que componen el cuento. Allí se debaten y chocan, en ese espacio vacío, las enunciaciones; a través de él transcurre un discurso «omitido», hecho por el contrapunto de los otros, en el que se concentra la significación del texto. 
los de Walsh. En todos ellos subyace la conciencia de la imposibilidad del triunfo de la verdad en el sistema, la frustración de toda espera en el restablecimiento de la justicia; si se admite que la novela negra propone una lectura de un mundo agobiado por la inseguridad de la existencia, nada más ejemplificador de esto que el relato del fusilamiento de inocentes atrapados por azar en la pesadilla de Operación masacre.

Sin embargo, los mecanismos del relato policial, de los que parecen dar cuenta especialmente los tres textos de no ficción, sufren, en contacto con el género periodístico, modificaciones que problematizan su condición; por ejemplo, la categoría de personaje, en este caso el de protagonista (el detective privado, un antihéroe como Marlowe, que Chandler define en $E l$ simple arte de matar ${ }^{19}$ ) se complejiza en textos como Operación masacre o ¿Quién mató a Rosendo?, en los que el investigador-periodista oscila constantemente entre la condición de personaje-narrador y autor. Se hace necesario interrogarse sobre la posibilidad de elaborar nuevos modos de explicitar las ambivalentes formas surgidas de la confrontación de elementos ficcionales con los provenientes de lo real y de cuestionar las formulaciones dadas, exclusivamente, a partir de sistemas narrativos de ficción.

Pero la propuesta más interesante de estos textos se produce como resultado de la destrucción operada, a partir del encuentro y diálogo de los diferentes géneros, en el verosímil de cada uno de ellos. La nueva forma, el relato de no ficción, se genera a partir del choque de los códigos policial y periodístico; en este enfrentamiento quedan al descubierto las convenciones que los sostienen.

Se ha visto ya cómo los textos implican un rechazo del realismo y de su concepción de la verosimilitud: mientras el código realista pretende que la ficción se lea como un reflejo de lo real, y para ello recurre a un sistema de convenciones que «verosimilizan» el relato, lo hacen creíble, Walsh opera una inversión sobre esto; trabaja con un material proveniente de la realidad e insiste en la condición casi inverosímil de esos hechos. Recurre a un género fuertemente formalizado, como es el policial, en el que prima la obediencia a las leyes de verosimilitud interna, las que hacen aceptar como posible lo increíble. Esta exasperación del código, que actúa "verosimilizando lo imposible», interesa a Walsh desde sus primeros textos: en las tres novelas policiales reunidas en Variaciones en rojo, siempre hay varias interpretaciones, muy aceptables, pero falsas, del enigma, hasta

${ }^{19}$ R. Chandler, El simple arte de matar (Barcelona: Bruguera, 1980): «... por estas calles bajas tiene que caminar el hombre que no es bajo él mismo, que no está comprometido ni asustado... Debe ser... un hombre de honor por instinto... El relato es la aventura de este hombre en busca de una verdad oculta» (pp. 215-216). 
que el detective aficionado hace una lectura correcta de los indicios y da la versión final «verdadera», pero en alguna medida menos creíble que las anteriores. La premisa de que lo cierto nunca es verosímil se mantiene en los textos de no ficción, sólo que las versiones falsas y aceptadas fueron ya dadas por los representantes de la justicia, mientras el narrador se hace cargo de revelar la «improbable verdad» de los hechos reales. Y para asegurar esto se acerca al género periodístico (en el mismo narrador confluyen y se homologan las funciones del detective y del periodista) que permite la presentación de pruebas y proporciona garantías acerca de la realidad indudable de los sucesos.

Sin embargo, en un movimiento simultáneo, a la vez que se inserta en el género, toma distancia y pone de manifiesto el verosímil del código periodístico, puesto que éste también opera alterando lo real, que es su materia, al imponerle convenciones y construir su discurso (en apariencia objetivo y «desideologizado») por medio de un lenguaje fuertemente impregnado de fórmulas desgastadas, clisés y lugares comunes, con los que se verosimiliza la realidad, se la enmascara y se la reduce a «lo aceptable», a «lo que debe ser», es decir, a lo posible. Walsh destruye este sistema tanto porque opera contra ese lenguaje, ya desprovisto de fuerza significante ${ }^{20}$, como porque habla acerca de lo que el periodismo soslaya ${ }^{21}$.

Es decir, que al mismo tiempo que recurre a códigos conocidos (policial, periodístico, relato de ficción), al ponerlos en contacto, al establecerse el diálogo y la lucha, destruye las convenciones que sustentan la ilusión, el pacto que cada uno de ellos sostiene con el lector, quien es obligado constantemente a revisar su competencia literaria. Si bien los textos participan de lo policial, nada hay para deducir, ningún misterio por descubrir, el cómo y el porqué ya se conocen, el juego deductivo y el reconocimiento de las pautas del verosímil del género se diluyen frente a la presión del referente real, privativo del periodismo, cuyos mecanismos discursivos, a su vez, son cuestionados por otros provenientes de la narrativa ficciconal; pero, por otra parte, las categorías establecidas por ésta sufren también, como se ha visto, una complejización por el contacto con el material que no proviene ya de lo imaginario.

${ }^{20}$ Como ejemplo pueden compararse los procedimientos constructivos y lingüísticos de su Caso Satanowsky con la anónima publicación Crimen Satanowsky (Buenos Aires: Ed. Verdad, 1958).

${ }^{21}$ «Esta es la historia que escribo en caliente..., pero que se me va arrugando día a día en el bolsillo porque la paseo por todo Buenos Aires y nadie me la quiere publicar, y casi ni enterarse... A doce años de distancia... se pueden revisar las colecciones de los diarios y esta historia no existió ni existe.» Operación masacre, Prólogo a la tercera edición, p. 11. 
Se está frente a textos que pretenden desautomatizar los modos de lectura, modificando una práctica orientada a la consumición pasiva, desprovista de toda peligrosidad e influencia real sobre el receptor. Desde esta perspectiva, sería necesario considerar las relaciones que plantean entre literatura y política, entendiéndolas desde un punto de vista no exclusivamente temático, del significado expreso, sino como una acción ejercida por una forma nueva que tiende a destruir códigos de lectura aceptados y que, a la vez, exige replantear la validez de ciertas conceptualizaciones del campo de la teoría literaria.

\section{LA PROBLEMATIZACIÓN DE LO LITERARIO: FORMA Y FICCIÓN}

Los críticos norteamericanos consideran al género como un sistema en difícil equilibrio entre los elementos referenciales y el uso de procedimientos literarios y periodísticos; en general, se limitan a clasificar y describir los textos, centrándose en el problema de las técnicas usadas y en el de la mayor o menor «objetividad» y prescindencia periodística del narrador. Mas'ud Zavarzadeh ${ }^{22}$ propone el concepto de literatura fictual, en tanto la novela de no ficción está compuesta de elementos fácticos y ficcionales, es decir, que es bi-referencial; si la incidencia de cualquiera de sus dos ejes es superior al otro, desaparece la tensión entre los términos y se inclina ya sea al texto periodístico o al de ficción. Se trata de una forma narrativa que escapa a los encuadres descriptivos comunes: los dos campos, el imaginario y el real, actúan al mismo tiempo sobre el lector, manteniendo un contrapunto que permite la oscilación alternativa entre las lecturas, ya sea privilegiando la documental o la ficcional (posibilidad prevista por Walsh en el prólogo a ¿Quién mató o Rosendo? ${ }^{23}$ ), aun cuando la presencia simultánea de ambos términos en la recepción es la que les otorga riqueza significativa y problematiza el estatuto del género. La propuesta de Zavarzadeh tiene la validez de acercar la reflexión a los problemas teóricos específicos que plantean estos textos, como son el de la constitución de una forma, que va más allá de la elección de ciertas técnicas narrativas o periodísticas, y el de las complejas relaciones entre realidad y ficción, que no quedan resueltas constatando la existencia de una tensión entre ambas.

${ }^{22}$ Mas'ud Zavarzadeh, The Mythopoeic Reality. The Postwar American Nonfiction Novel (University of Illinois Press, 1976).

${ }^{23}$ «Si alguien quiere leer este libro como una simple novela policial, es cosa suya." ¿Quién mató a Rosendo? (Buenos Aires: Ed. Tiempo Contemporáneo, 1969), p. 9. 
El concepto de forma es uno de los más conflictivos en el ámbito de la discusión teórica; si se considera que la forma es también contenido (a través de ella «el creador toma posición activa con respecto al contenido», puesto que «la elección de ambos procede de un mismo acto» ${ }^{24}$ ), no puede aceptarse la opinión de que estos textos estén compuestos por un tema al que se le dio «forma literaria» mediante la aplicación de algunas técnicas.

La significación del texto se da a través de la forma, ella es significante en sí misma, trasciende el contenido y tampoco es, simplemente, un conjunto de procedimientos que, como tales, permanecen apartados de lo histórico. La forma, en cambio, se encuentra estrechamente relacionada con los cambios históricos y sociales y, por lo tanto, en ella está la ideología del texto. De este modo, en Walsh la construcción de una nueva forma de ruptura con respecto a otros códigos y sistemas literarios implica ya una evaluación ideológica, una toma de posición, no sólo en relación al referente, sino también a la literatura, su función y los materiales con los que ésta se construye; desde allí entabla la polémica con las concepciones para las cuales sus textos serían únicamente periodísticos.

Determinan su inserción en la extensa tradición de la literatura política argentina, tanto el referente elegido como la forma (constituida igualmente por los procedimientos como por el contenido); en el estudio de ella, del tipo de trabajo de transformación que se ha producido, es donde podrá encontrarse la especificidad de estos textos y su fuerza significativa. Es la forma de estos relatos, el modo en que el discurso asume un referente que estaba silenciado, lo que problematiza y obliga a repensar qué es lo que hace al texto literario, por qué o cómo serían leídos Operación masacre o Caso Satanowsky en otra época o en otras culturas, por las cuales podrían ser aceptados como ficciones los sucesos que se narran.

En este encuentro de lo ficticio con lo real se abre la otra rica polémica que posibilitan estos textos: qué tipo de relaciones mantiene la ficción con la realidad, cuáles son los atributos de la ficcionalidad; suele pensarse que ella es un elemento esencial de la literatura, especialmente en el caso de la narrativa; lo cierto es que las actitudes frente al discurso ficcional cambian en las diferentes culturas. Pero lo que se percibe como transgresivo en los relatos de no ficción es que el límite se destruya y el referente, al mismo tiempo que cumple el requisito de ser verdadero, parezca ficcionalizarse y participar de los rasgos de lo imaginario.

La reflexión sobre el estatuto de estos relatos exige interrogarse sobre

${ }^{24} \mathrm{~V}$. Voloshinov, "Le discours dans la vie et le discours dans la poésie», en T. Todorov, M. Baitin: Le principe dialogique (Paris: Ed. du Seuil, 1981). 
la condición de la ficción y plantear, en primer lugar, si la transformación ejercida por la forma sobre el material referencial (condición para su literaturidad) implica necesariamente la ficcionalización de los textos.

La ficcionalidad no es una propiedad sintáctica o semántica específica, depende de una serie de normas y convenciones que legitiman la línea que separa la ficción de lo que no lo es, condicionadas por valores culturales determinantes, a su vez, de los modos de lectura. Si la ficción es el resultado de la intersección de «las convenciones de ficcionalidad con las normas de la institución literaria» ${ }^{25}$, es decir, del uso de ciertos procedimientos de construcción, reconocidos por el consenso general, para la constitución de un espacio ficticio, se hace necesario examinar cómo se dan esas condiciones de ficcionalidad o qué modificaciones sufren en los textos de Walsh. Se impone una revisión de las categorías que, hasta ahora, han sido analizadas exclusivamente en obras ficcionales: por ejemplo, la presencia, en el relato de ficción, de un espacio de enunciación determinado por «la duplicación o desdoblamiento de los constituyentes de la situación comunicativa» ${ }^{26}$, es decir, por un claro deslinde entre autor y narrador; esto se complejiza en el caso de la no ficción por el constante deslizamiento entre la función de sujeto de la enunciación que «narrativiza» los hechos y la de periodista-detective real, responsable de la investigación.

Lo mismo que con respecto al rol del narrador ocurre en el ámbito del enunciado, puesto que los textos se refieren a sucesos comprobables y personas reales; sin embargo, hay una organización que podría considerarse ficcional en tanto recurre a procedimientos (escenas, situaciones narrativas, suspense, etc.) provenientes del relato policial o de ficción que determinan un particular modo de transformación del referente.

La forma de intersección de ambos mundos, ficcional y real, la diferente «manera de ser» en ellos de los objetos, el porqué de la presencia de elementos ficcionales en la narrativa de no ficción, así como la actitud que producen en la recepción, oscilante siempre entre las dos instancias, proporciona un amplio campo para la reflexión teórica, cuyos resultados exceden el ámbito específico de estos relatos. Interesan también para otros sistemas narrativos, en tanto que las relaciones entre lo real y lo imaginario varían de acuerdo a los géneros, la historia y las diferentes concepciones de la literatura. El trabajo sobre los textos de Walsh aporta elementos para resolver algunos de estos interrogantes $y$, a la vez, permite

${ }^{25}$ W. Mignolo, «Semantización de la ficción literaria», en Dispositio, vols. V-VI, núms. 15-16 (1981).

${ }^{26}$ S. de Rivarola, «Ficcionalidad, referencia, tipos de ficción literaria», en Lexis, vol. III, núm. 2 (diciembre 1979). 
comprobar el grado de interdependencia existente (en cuanto a procedimientos, construcción, etc.) en la totalidad de su obra y rechazar el confinamiento de parte de sus relatos como pertenecientes a un género no literario.

Se hace necesario, entonces, replantear el lugar, en el contexto de la literatura argentina, que corresponde a la producción de Rodolfo Walsh, en la medida en que textos como éstos asumen un compromiso de reflexión en torno a lo real tanto como sobre la práctica significante llamada literatura, cuyos límites no tienen por qué ser precisos o fijados de antemano. Plantean nuevos espacios para el ejercicio de esa práctica, nuevos. interrogantes, polemizan y abren una implícita propuesta, cuya acción se ejerce, como se ha visto, en diferentes niveles: en primer término, aportan nuevas vías a la narrativa (iniciando una forma que reemplace al relato de ficción tradicional y establezca otro tipo de relación entre el arte y la política).

Este proyecto, en segundo lugar, rechaza la condición inofensiva de la literatura y revierte en un intento de cambio de los modos de recepción, para evitar que el lector resulte un pasivo consumidor de «denuncias sociales»; por último, impulsa la reflexión en torno a problemas teóricos, obligando a revisar categorías que se complejizan, no sólo por su presencia en los textos de no ficción, sino por la continuidad que se establece entre ellos y el resto de su producción. El análisis de ésta permitiría aportar elementos para la elaboración de una teoría que intentara dar cuenta de otros textos de no ficción y ayudara a explicitar los mecanismos de transformación de lo real en la literatura.

En esta capacidad de propuesta, en esa riqueza significativa, que le permite abrir nuevos caminos, radica la vitalidad de su escritura, su vigencia, es decir, su triunfo sobre la muerte. 
